\title{
Multivariate Repeated Measures Analysis of Plant Growth Regulators on Tradescantia virginiana
}

\author{
Sarah A. White, ${ }^{1}$ Holly L. Scoggins,${ }^{2}$ Richard P. Marini, ${ }^{3}$ and \\ Joyce G. Latimer ${ }^{4}$ \\ Department of Horticulture, Virginia Tech, Blacksburg, VA, 24060
}

Additional index words. spiderwort, plant growth regulators, herbaceous perennials, Topflor, Bonzi, Sumagic, repeated measures

\begin{abstract}
Little information is available on cultural requirements for greenhouse production of Tradescantia virginiana L. We tested three plant growth regulators (PGRs) at ascending rates on T. virginiana 'Angel Eyes,' 'Blue Stone,' and 'Red Cloud' in an effort to find appropriate application levels for height suppression. Treatments applied two weeks after transplant. Each PGR was applied once at the following rates: paclobutrazol at 0, 40, 80, 120 , or $160 \mathrm{mg} \cdot \mathrm{L}^{-1}$, uniconazole at $0,15,30,45$, or $60 \mathrm{mg} \cdot \mathrm{L}^{-1}$, or flurprimidol at $0,15,30$, 45, 60, or $75 \mathrm{mg} \cdot \mathrm{L}^{-1}$. Repeated measures experimental design and multivariate analysis was used to examine plant responses to PGRs over time. The most effective paclobutrazol rate for adequate height suppression was $120 \mathrm{mg} \cdot \mathrm{L}^{-1}$. Uniconazole at 30 to $45 \mathrm{mg} \cdot \mathrm{L}^{-1}$ and flurprimidol at 45 to $60 \mathrm{mg} \cdot \mathrm{L}^{-1}$ resulted in adequate height control. 'Blue Stone' and 'Red Cloud' appeared more responsive (greater suppression of height at rates applied) to both uniconazole and flurprimidol than 'Angel Eyes.' These results suggest that cultivars respond in a different manner to PGRs applied to them; more compact growth can be obtained for cultivars tested using these suggested rates. Chemical names used: trifuloromethoxy phenyl-5-pyrimidinemethanol (flurprimidol); [( \pm$)-\left(\mathbf{R}^{*}, \mathbf{R}^{*}\right)-\mathbf{B}-((4-\mathrm{chlorophenyl)}$ methyl)-?(1,1,-dimethylethyl)-1H-1,2,4,-triazole-1-ethanol)] (paclobutrazol); uniconazole.
\end{abstract}

Tradescantia virginiana (spiderwort) is an herbaceous perennial native to eastern and central North America. As a garden plant, it has proved well adapted to sun and shade as well as both wet and dry areas. These characteristics, along with the numerous cultivars available and extended flowering period during the summer, make them good landscape plants. In the landscape, the vigorous and spreading growth habit of spiderwort is desirable, but container production can be a challenge. Foliage often outgrows the pot and becomes unsightly and lodges. This characteristic, especially noticeable late in the summer season, reduces crop marketability. A method of temporarily suppressing vegetative growth in the greenhouse or nursery, before retail sale, would improve the appearance of the plants and possibly enhance sales. Little information is available concerning the cultural requirements of $T$. virginiana. No published research exists on use of plant growth regulators (PGRs) on spiderwort.

Received for publication 2 Aug. 2004. Accepted for publication 4 Oct. 2004. Use of trade names does not imply endorsement of named products nor criticism of similar ones not named. acknowledged. This paper is from a thesis submitted by the senior author in partial fulfillment of the requirements for the MS degree. The authors gratefully acknowledge the technical assistance of Velva Groover. Plant material generously provided by Yoder Green Leaf, Lancaster, Pa. Multivariate repeated measures analysis of plant growth regulators on Tradescantia virginiana.

${ }^{1}$ Former graduate student, currently graduate research assistant in the Biological Sciences Department, Clemson University, Clemson, SC 29634.

${ }^{2}$ Assistant professor; e-mail hollysco@vt.edu.

${ }^{3}$ Professor. Current address: Pennsylvania State University, University Park, PA 16802.

${ }^{4}$ Professor.
Flurprimidol (FLU), paclobutrazol (PAC), and uniconazole (UNI) are PGRs that control plant growth by inhibiting the synthesis of gibberellins and their effects on ornamental plants have been examined in numerous studies. Response to application of PGRs is dependent upon the species. Plant height may be suppressed with or without bloom delay. Pobudkiewiczand Nowak(1994) studied Dianthus caryophyllus L. 'Snowmass' and obtained desirable height control with no reduction in flower size or number with foliar applications of 15 and $22.5 \mathrm{mg} \cdot \mathrm{L}^{-1}$ FLU. Consistent suppression of vegetative and flower stalk growth of Canna $\times$ generalis L.H. Bail. 'Florence Vaughn' was attained with foliar application of FLU at $50 \mathrm{mg} \cdot \mathrm{L}^{-1}$, but the suppression of flower stalk growth greatly reduced the salability of the plant (Bruner et al., 2000). Buddleia davidii Franch. 'Royal Red' treated with FLU as a foliar spray at $62.5 \mathrm{mg} \cdot \mathrm{L}^{-1}$ had suppressed shoot growth over a short time without any delay in flowering (Keever and Gilliam, 1994).

Foliar applications of paclobutrazol at rates of 25 or $100 \mathrm{mg} \cdot \mathrm{L}^{-1}$ to Verbena rigida Spreng. suppressed plant height without affecting time to flower (Davis and Andersen, 1989). Dutch-grown bleeding hearts [Dicentra spectabilis (L.) Lem.] had delayed flowering with PAC foliar application at $50 \mathrm{mg} \cdot \mathrm{L}^{-1}$; however, treatment resulted in darker green coloration of the leaves and adequate height control (Kim et al., 1999). Foliar UNI application at $15 \mathrm{mg} \cdot \mathrm{L}^{-1}$ to Oenothera fruticosa $\mathrm{L}$. resulted in a $31 \%$ reduction in plant height at flowering compared with controls and flower diameter was reduced by $36 \%$ (Clough et al., 2001). Gibson and Whipker (2001) reported that increasing the concentrations of UNI (2, $4,8,16$, or $32 \mathrm{mg} \cdot \mathrm{L}^{-1}$ ) foliar sprays reduced plant height in a linear manner for both 'Osaka White' and 'Nagoya Red' ornamental cabbage (Brassica oleracea var. acephala L.).

Researchers in tree fruits, forestry, and other fields requiring long-term measurements frequently use repeated measures analysis of variance to compare responses of the same experimental unit over time or space (Fernandez, 1991). Plant growth regulator studies on herbaceous ornamentals often use a point-in-time general linear model (GLM) analysis. Most of these experiments are relatively short-term, and these analyses provide comparisons among treatments at a certain point-market-ready, anthesis, or some other event. An exception is described by Littell (1989) in his discussion of PGR work on chrysanthemum. In this case, the use of repeated measures analysis revealed differences in PGR effects depending on the rate of growth (fast vs. slow). The main advantage of the repeated measures design is that it controls for subject heterogeneity, that is, individual differences. There are benefits of taking into account the initial or previous measurement (e.g., height) as a factor, though this results in a more complicated covariance structure (Littell et al., 1998). But recent advances in statistical methods make for efficient and effective analysis of data. One method is to use the REPEATED statement of SAS's general linear model (GLM) procedure (SAS Institute Inc., Cary, N.C.). Even short-term studies on nursery and greenhouse crops such as this one can benefit from examination of response trends over time. This study examines the effect of PAC, UNI, and FLU on height, width, and flowering of $T$. virginiana plants as measured over time.

\section{Materials and Methods}

The experiments were conducted in a double-layer polyethylene-covered house (25 Mar. to 20 May 2002). Preliminary screenings revealed rapid spring growth of $T$. virginiana with flowering plants of marketable size produced from liners in $<6$ weeks (data not shown). Three cultivars of $T$. virginiana were used in this experiment: Blue Stone, Angel Eyes, and Red Cloud (54 cell size; Yoder Greenleaf Perennials, Leola, Pa.). One hundred vernalized liners per cultivar were planted each in $10.8-\mathrm{cm}$-diameter $\left(1180 \mathrm{~cm}^{3}\right)$ plastic containers using media containing: $65 \%$ to $75 \%$ bark fines, $20 \%$ to $25 \%$ Canadian sphagnum peatmoss, $9 \%$ to $15 \%$ perlite and a proprietary starter charge (Sierra Perennial Mix, Scott's Co., Merrifield, Ohio) on 11 Mar. 2001. Throughout the experiment, irrigation and fertilizer $\left(15 \mathrm{~N}-6.9 \mathrm{P}-14.1 \mathrm{~K}\right.$ at $200 \mathrm{mg} \cdot \mathrm{L}^{-1}$ nitrogen, applied as constant liquid feed) was applied to the entire study at an equal volume (350 mL/pot) at each irrigation. Three days before PGR application, 88 uniform plants per cultivar were selected. Each PGR was considered to be an experiment. We used a factorial treatment design of three cultivars $\times$ five or six rates of PGRs. The experimental design was a randomized complete block with 
four replicates per PGR treatment. Plants were blocked on the basis of shoot number and plant height.

Two weeks after transplant, PGRs were applied to actively growing plants using a handheld $\mathrm{CO}_{2}$ pressurized sprayer ( $\mathrm{R} \& \mathrm{D}$ Sprayer, Opelousas, La.) with an 800VS nozzle at 18 p.s.i. When PGRs were applied, the weather was partly cloudy and the temperature was $33{ }^{\circ} \mathrm{C}$ with $22 \%$ relative humidity. Each PGR solution was evenly applied as a foliar spray at $210 \mathrm{~mL} \cdot \mathrm{m}^{-2}$ [manufacturers suggested rate $\left(62 \mathrm{~mL} \cdot \mathrm{m}^{-2}\right)$ ] over a $1-\mathrm{m}^{2}$ area containing four plants from each treatment. The PGRs applied were PAC (Bonzi, Syngenta Chem. Co. Greensboro, N.C.) at $0,40,80,120$, and $160 \mathrm{mg} \cdot \mathrm{L}^{-1}$; UNI (Sumagic, Valent USA Corp. Marysville, Ohio) at $0,15,30,45$, and $60 \mathrm{mg} \cdot \mathrm{L}^{-1}$; and FLU (TopFlor, SePRO Corp. Carmel, In.) at 0, $15,30,45,60$, and $75 \mathrm{mg} \cdot \mathrm{L}^{-1}$. Data collected included plant height $(\mathrm{cm}$, from rim of pot to top of foliage), average width (cm, at widest point and perpendicular to that point), and percent plants flowering. The growth habit of $T$. virginiana presented a challenge in measuring plant height - after an increase in height from weeks 0 to 2, foliar growth tipped downward, resulting in values nearly equal to or slightly less than the week two measurement. Stem growth increased from weeks 4 to 6 , with no further drooping of the foliage.

Response variables (plant height, plant width, and percent plants flowering) were measured every two weeks. Measurements taken over time on the same plants are often correlated. Univariate analysis of variance (ANOVA) $\mathrm{F}$ tests for effects involving week and interactions with week rely on the HuynhFeldt (H-F) condition (Huynh and Feldt, 1970). The H-F condition requires a certain correlation structure between all pairs of measurements. Sphericity test using the PRINTE option of the REPEATED statement of SAS's GLM Procedure evaluate the H-F condition (Marini et al., 1995). Because the hypothesis of sphericity test for all three response variables was rejected $(P=0.006,<0.001$, and $<0.001$, respectively) these data were analyzed with a multivariate repeated-measures analysis using the REPEATED statement of SAS's GLM procedure (SAS Institute Inc. Cary, NC). No assumptions about repeated measures covariance structure are required by multivariate analysis (Marini et al., 1995). The $P$ values from the multivariate ANOVA (MANOVA) are presented for the main effect of WEEK and all interactions involving WEEK. The $P$ values based on Wilk's Lambda for response variables main effects were obtained with tests of hypotheses for between-subject effects from repeated measures ANOVA. The $P$ values generated in the REPEATED statement of SAS's GLM Procedure as follows:

proc glm data = trans;

class color rate;

model $w k 1$ wk2 $w k 3=$ color rate color $\times$ rate/nouni; repeated week (1 23 3) polynomial/summary; with the PROFILE transformation of the SUMMARY option are also presented for contrast variables (Marini et al., 1995).

\section{Results and Discussion}

Paclobutrazol. Pooled over all cultivars and PAC rates, all three response variables changed significantly over time (Table 1). The main effect of cultivar significantly influenced flowering, but not plant height or width. Withinsubject effects test the hypothesis that response variables do not change over time, whereas between-subject effects test the hypothesis that treatments do not affect the response variables when averaged over time. The week $\times$ PAC rate interaction was significant for plant height and width, but not flowering. Averaged over all cultivars, the increase in plant height was negatively related to PAC concentration; the relationship was quadratic between weeks 2 and 4 and linear between weeks 4 and 6 (Table 2 ). The increase in plant width from week 4 to 6 was negatively related to PAC concentration in a linear manner $(P=0.056)$.

'Blue Stone' was slightly smaller than 'Angel Eyes' after height comparison without taking into account the effect of week (Table 1). $\times$ cultivar and week $\times$ rate) were significant (Table 1). From week 4 to 6 'Angel Eyes' width increased more than 'Blue Stone' (data not preFor plant width, two 2-way interactions (week

sented). The control plant's diameter increased more from week 4 to 6 than week 2 to 4 , but the opposite was true for plants treated with higher PAC rates (Tables 2). Paclobutrazol did not affect the percentage of plants flowering. The percentage of plants flowering differed by cultivar. For 'Blue Stone' and 'Red Cloud' the percentage of plants flowering increased during the experiment, but 'Angel Eyes' did not flower (Table 3).

The PAC rate that was most effective at controlling plant height was $120 \mathrm{mg} \cdot \mathrm{L}^{-1}$, without regard for cultivar. At this rate, plant height was $26.5 \%$ less than the nontreated control. Width of cultivars differed, but at $120 \mathrm{mg} \cdot \mathrm{L}^{-1} \mathrm{PAC}$, width of 'Angel Eyes' was suppressed by $14 \%$, 'Blue Stone' by $21 \%$, and 'Red Cloud' by $14 \%$ when compared with controls at 6 weeks after treatment. Application of PAC did not delay or inhibit flowering. No phytotoxicity was noted for any PAC rate. Unlike our study, Wulster and Ombrello(2000) noted significant delays in flowering time of Ixia L. hybrids after application of PAC at 100 or $200 \mathrm{mg} \cdot \mathrm{L}^{-1}$, but Cox and Keever (1988) noted foliar application of PAC to Pelargonium $\times$ hortorum L.H. Bail. at 20 or $40 \mathrm{mg} \cdot \mathrm{L}^{-1}$ did not affect days to flowering.

Uniconazole. Plant height was influenced

Table 1. Sources of variation and $P$ values from analysis of variance and multivariate analysis of variance for effect of paclobutrazol (PAC) on height, width, and arcsine transformed flowering of Tradescantia virginiana over 6 week experiment. $\mathrm{RC}=$ 'Red Cloud'; $\mathrm{AE}=$ 'Angel Eyes'; BS = 'Blue Stone'.

\begin{tabular}{lcrrrr}
\hline & & & \multicolumn{3}{c}{ Response variable } \\
\cline { 4 - 6 } Source of variation & NDF & DDF & Ht & Width & Flowering \\
\hline Week $^{z}$ & 2 & 44 & $<0.001$ & $<0.001$ & $<0.001$ \\
Cultivar $^{y}$ & 2 & & 0.073 & 0.117 & $<0.001$ \\
RC vs. AE $^{y}$ & 1 & 0.162 & 0.090 & 0.001 \\
RC vs. BS & 1 & & 0.364 & 0.843 & 0.001 \\
AE vs. BS & 1 & & 0.024 & 0.059 & $<0.001$ \\
Cultivar $\times$ rate & 8 & & 0.961 & 0.548 & 0.534 \\
Week $\times$ cultivar & & & 0.819 & 0.022 & $<0.001$ \\
Week $\times$ PAC rate & 4 & 88 & 0.011 & 0.004 & 0.505 \\
$\quad$ Week $\times$ rate linear & & 4 & 0.001 & 0.001 & 0.577 \\
$\quad$ Week $\times$ rate quadratic $^{z}$ & 2 & 44 & 0.082 & 0.029 & 0.862 \\
Week $\times$ RC vs. AE & 2 & 44 & 0.899 & 0.259 & 0.008 \\
Week $\times$ RC vs. BS & 2 & 44 & 0.741 & 0.105 & 0.006 \\
Week $\times$ AE vs. BS & 2 & 44 & 0.475 & 0.006 & $<0.001$ \\
\hline
\end{tabular}

${ }^{\mathrm{z}}$ Results from MANOVA tests of hypothesis for within-subject (measurement taken repeatedly on each plant) effects.

yTests the hypothesis that treatments (between-subjects effects) have no effect on the response variables, ignoring within-subject effects. This is the treatment effect averaged over all weeks.

Table 2. Effect of paclobutrazol(PAC) rate on average plant height and width of three Tradescantia virginiana cultivars. Lower table represents $P$ values from profile analysis of plant height and width. These analyses of variance are for the transformed variables representing the differences between adjacent weeks.

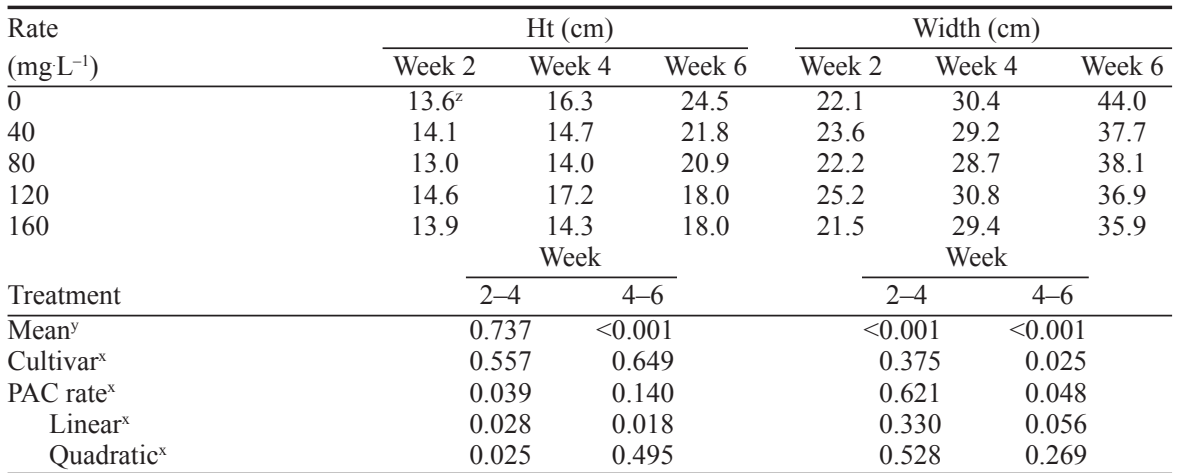

${ }^{\mathrm{z}}$ Average of all cultivars and replications for each treatment level and week.

${ }^{y} P$ values for change in plant height and width for adjacent weeks pooled over all treatments.

${ }^{x} P$ values for the main effects and interactions on the change in plant height and width between adjacent weeks. 
Table 4. Sources of variation and $P$ values from analysis of variance and multivariate analysis of variance for effect of uniconazole (UNI) rate on height, width, and arcsine transformed flowering of Tradescantia virginiana plants over 6 week experiments. $\mathrm{RC}=$ 'Red Cloud'; $\mathrm{AE}=$ 'Angel Eyes'; BS $=$ 'Blue Stone'.

\begin{tabular}{|c|c|c|c|c|c|}
\hline \multirow{2}{*}{$\begin{array}{l}\text { Source of } \\
\text { variation }\end{array}$} & \multirow[b]{2}{*}{$\mathrm{NDF}$} & \multirow[b]{2}{*}{ DDF } & \multicolumn{3}{|c|}{ Response variable } \\
\hline & & & $\mathrm{Ht}$ & Width & Flowering \\
\hline$\overline{\text { Week }^{z}}$ & 2 & 44 & $<0.001$ & $<0.001$ & $<0.001$ \\
\hline Cultivar $^{\mathrm{y}}$ & 2 & & 0.121 & 0.069 & $<0.001$ \\
\hline UNI rate $y$ & 4 & & 0.009 & 0.005 & 0.453 \\
\hline Linear $^{\mathrm{y}}$ & 1 & & 0.002 & 0.002 & 0.084 \\
\hline Cultivar $\times$ rate $^{y}$ & 8 & & 0.027 & 0.553 & 0.865 \\
\hline $\mathrm{RC}$ vs. $\mathrm{AE}^{\mathrm{y}}$ & 1 & & 0.127 & 0.021 & 0.007 \\
\hline RC vs. $\mathrm{BS}^{\mathrm{y}}$ & 1 & & 0.653 & 0.218 & 0.026 \\
\hline $\mathrm{AE}$ vs. $\mathrm{BS}^{\mathrm{y}}$ & 1 & & 0.051 & 0.263 & $<0.001$ \\
\hline $\mathrm{AE}$ vs. $\mathrm{BS} \times \mathrm{UNI}$ rate $^{\mathrm{y}}$ & 1 & & 0.048 & 0.448 & 0.720 \\
\hline Week $\times$ cultivar $^{z}$ & 4 & 88 & 0.001 & $<0.001$ & $<0.001$ \\
\hline Week $\times$ UNI rate ${ }^{z}$ & 8 & 88 & 0.014 & 0.002 & 0.002 \\
\hline Week $\times$ rate linear ${ }^{z}$ & 2 & 44 & 0.001 & 0.002 & 0.002 \\
\hline Week $\times$ RC vs. $\mathrm{AE}^{\mathrm{z}}$ & 2 & 44 & 0.944 & 0.001 & 0.001 \\
\hline Week $\times$ RC vs. BS $^{z}$ & 2 & 44 & 0.001 & 0.004 & 0.004 \\
\hline Week $\times$ AE vs. BS $^{z}$ & 2 & 44 & 0.001 & $<0.001$ & $<0.001$ \\
\hline
\end{tabular}

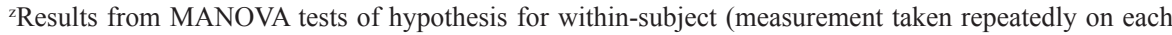
plant) effects.

yTests the hypothesis that treatments (between-subjects effects) have no effect on the response variables, ignoring within-subject effects. This is the treatment effect when averaged over all weeks.

Table 3. Effect of paclobutrazol (PAC) rate on arcsine transformed flowering of Tradescantia virginiana. . Lower table represents $P$ values from profile analysis of plant height and width. These analyses of variance are for the transformed variables representing the differences between adjacent weeks.

\begin{tabular}{|c|c|c|c|c|c|c|}
\hline \multirow[b]{2}{*}{ Cultivar } & \multirow{2}{*}{$\begin{array}{c}\text { Rate } \\
\left(\mathrm{mg} \cdot \mathrm{L}^{-1}\right)\end{array}$} & \multicolumn{5}{|c|}{ Arcsine transformed flowering } \\
\hline & & Week 2 & & Week 4 & & Week 6 \\
\hline \multirow[t]{5}{*}{ ‘Angel Eyes' (AE) } & 0 & $0^{\mathrm{z}}$ & & 0 & & 0.393 \\
\hline & 40 & 0 & & 0 & & 0 \\
\hline & 80 & 0 & & 0 & & 0 \\
\hline & 120 & 0 & & 0 & & 0 \\
\hline & 160 & 0 & & 0 & & 0 \\
\hline \multirow[t]{5}{*}{ 'Blue Stone' (BS) } & 0 & 0 & & 0.785 & & 1.178 \\
\hline & 40 & 0 & & 0.785 & & 1.571 \\
\hline & 80 & 0.393 & & 1.178 & & 1.571 \\
\hline & 120 & 0 & & 0.393 & & 1.178 \\
\hline & 160 & 0 & & 1.178 & & 1.571 \\
\hline \multirow[t]{6}{*}{ 'Red Cloud' (RC) } & 0 & 0 & & 0.393 & & 0 \\
\hline & 40 & 0 & & 0 & & 1.178 \\
\hline & 80 & 0 & & 0.785 & & 0.393 \\
\hline & 120 & 0 & & 0.785 & & 0.393 \\
\hline & 160 & 0 & & 0.785 & & 0.785 \\
\hline & & & & Week & & \\
\hline \multicolumn{2}{|l|}{ Treatments } & & $2-4$ & & $4-6$ & \\
\hline \multicolumn{2}{|l|}{ Mean $^{y}$} & & $<0.001$ & & 0.512 & \\
\hline \multicolumn{2}{|l|}{ Cultivar ${ }^{\mathrm{x}}$} & & 0.002 & & 0.079 & \\
\hline \multicolumn{2}{|l|}{$\mathrm{RC}$ vs. $A E^{\mathrm{x}}$} & & 0.013 & & 0.761 & \\
\hline \multicolumn{2}{|l|}{ RC vs. $B^{x}$} & & 0.274 & & 0.038 & \\
\hline \multicolumn{2}{|l|}{$\mathrm{AE}$ vs. $\mathrm{BS}^{\mathrm{x}}$} & & 0.006 & & 0.073 & \\
\hline
\end{tabular}

${ }^{\mathrm{z}}$ Values are means of four replications for each treatment.

${ }^{y} P$ value for change in the arcsine transformed flowering plants for adjacent weeks pooled over all treatments. ${ }^{x} P$ values for the main effects and interactions on the change in arcsine transformed flowering plants between adjacent weeks.

by time and UNI rate, but not cultivar (Table 4). Height was also affected by the interactions for cultivar $\times$ rate, week $\times$ rate, and week $\times$ cultivar. The relationship between height and rate was different for only 'Angel Eyes' and 'Blue Stone,' where height suppression with increasing UNI rates was greatest for 'Blue Stone' (Table 5). Among cultivars, plant height change from week 2 to 4 was not related to rate, but from week 4 to 6 the amount the plants grew was suppressed in a linear decreasing manner as UNI rate increased (Table 5). From week 2 to 4 'Blue Stone'increased in height more than the other cultivars, but all three cultivars increased in height to a similar extent from week 4 to 6 (Table 5).

Plant width was influenced by week and rate and the interactions were significant for week $\times$ cultivar and week $\times$ UNI rate (Table 4 ). Pooled over cultivars, UNI appeared to suppress plant width with increasing effectiveness with increasing rate from week 2 to 4 , but UNI rate did not seem to impact the increase in width from week 4 to 6 (Table 5). The increase in width from week 2 to 4 was greatest for 'Red Cloud' and least for 'Angel Eyes,' but the opposite was true for week 4 to 6 (Table 5). The increase in flowering from week 2 to 4 was similar for 'Blue Stone' and 'Red Cloud,' but 'Angel Eyes' did not flower. The increase in flowering from week 4 to 6 was greatest for 'Blue Stone' and least for 'Angel Eyes.' From week 2 to 4, increasing rates appeared to decrease the percentage of plants flowering, but from week 4 to 6 , rate did not effect flowering (Table 5).

Response to UNI application depended on cultivar, and application rates need to be adjusted by cultivar vigor. Whipker et al. (1995) compared two cultivars of tuberous rooted dahlia [Dahlia variabilis hort. non (Willd.) Desf.] with drench UNI treatments and found 'Red Pygmy' height was maintained at a marketable level while that of 'Golden Emblem' was not. Effective height control of T. virginiana appeared to be achieved with UNI application at $45 \mathrm{mg} \cdot \mathrm{L}^{-1}$. In the present study, height of all cultivars was controlled; 'Blue Stone' height was suppressed by $45 \%$, 'Red Cloud' by $24 \%$ and 'Angel Eyes' by only 3\% when compared with nontreated controls at 6 weeks after treatment. At the same application level, width was $13 \%$, $23 \%$, and $49 \%$ less than the control for 'Red Cloud,' 'Blue Stone,' and 'Angel Eyes,' respectively. Uniconazole did not delay flowering of any cultivars, nor was any phytotoxicity noted. Kim etal.(1999) reported no phytotoxicity after UNI application at 1 or $5 \mathrm{mg} \cdot \mathrm{L}^{-1}$ to Dicentra spectabilis. Application of UNI at 5, 25, or 100 $\mathrm{mg} \cdot \mathrm{L}^{-1}$ to Verbena rigida resulted in no delay in flowering while height was controlled (Davis and Andersen, 1989).

Flurprimidol. Plant height was affected by week and FLU rate and the interactions of cultivar $\times$ FLU rate and week $\times$ FLU rate (Table 6). As FLU rate increased the height suppression of all cultivars increased linearly from week 4 to 6 (Table 7). Plant width was affected by week and cultivar, and the interactions of week $\times$ cultivar and week $\times$ FLU rate. The profile contrasts indicate that the cultivar $\times$ FLU rate interaction affected the increase in plant width $(P=0.052)$ (Table 8$)$. From week 2 to 4 the increase in width was greatest for 'Blue Stone' and from week 4 to 6 plant width increased least for 'Blue Stone'. The percentage of flowering plants was affected by week, cultivar, and the interaction of week $\times$ cultivar (Table 6). Increases in flowering from week 2 to 4 were similar for 'Blue Stone' and 'Red Cloud,' but 'Angel Eyes' did not flower. From week 4 to 6 flowering was greatest for 'Blue Stone' and least for 'Angel Eyes' (Table 8).

The most effective FLU application rate for control of $T$. virginiana height was $45 \mathrm{mg} \cdot \mathrm{L}^{-1}$. Flurprimidol effect on height was similar for all cultivars. After FLU application at $45 \mathrm{mg} \cdot \mathrm{L}^{-1}$, average height was $20 \%$ shorter than nontreated controls. Width of plants differed by cultivar. At the recommended rate, 'Angel Eyes' width was suppressed 10\%, 'Blue Stone' $15 \%$, and 'Red Cloud' $18 \%$. Flurprimidol rate did not affect time to flower or percentage flowering plants. A similar flowering response was noted with $\mathrm{Bud}$ dleia davidii 'Royal Red' (Keever and Gilliam, 1994) and Dianthus caryophyllus 'Snowmass' (Pobudkiewicz and Nowak, 1994).

\section{Summary}

Though PGR treatment effects were fairly modest, PAC, UNI, and FLU were all effective in suppressing $T$. virginiana height and width. The greatest suppression occurred during the 4 to 6 WAT period. The PROFILE 
Table 5. Effect of uniconazole (UNI) rate on response variables of Tradescantia virginiana. Lower table presents $P$ values from profile analysis of $T$. virginiana response variables after treatment with UNI at ascending rates. These analyses of variance are for the transformed variables representing the differences in height between adjacent weeks. Flowering data is arcsine transformed.

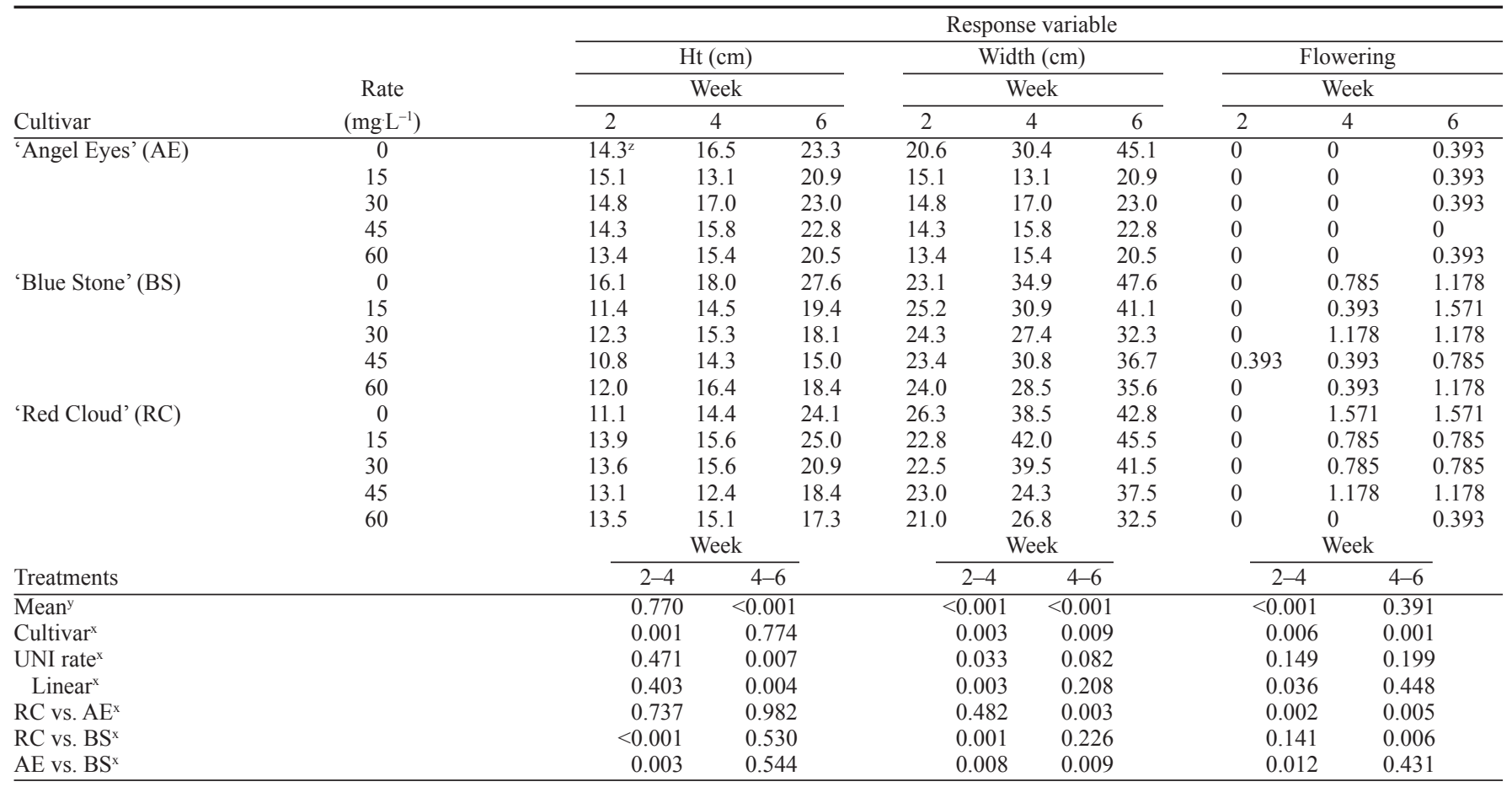

${ }^{z}$ Values are means of four replications for each treatment.

${ }^{y} P$ value for change in plant height for adjacent weeks pooled over all treatments.

${ }^{x} P$ values for the main effects and interactions on the change in plant height, width, and arcsine transformed flowering between adjacent weeks.

Table 6. Sources of variation and $\mathrm{P}$ values from analysis of variance and multivariate analysis of variance for effect of flurprimidol (FLU) rate on height, width, and arcsine transformed flowering of Tradescantia virginiana plants over 6 week experiments. $\mathrm{RC}=$ 'Red Cloud'; $\mathrm{AE}=$ 'Angel Eyes'; $\mathrm{BS}$ $=$ 'Blue Stone'.

\begin{tabular}{|c|c|c|c|c|c|}
\hline \multirow{2}{*}{$\begin{array}{l}\text { Source of } \\
\text { variation }\end{array}$} & \multirow[b]{2}{*}{ NDF } & \multirow[b]{2}{*}{ DDF } & \multicolumn{3}{|c|}{ Response variable } \\
\hline & & & $\mathrm{Ht}$ & Width & Flowering \\
\hline$\overline{\text { Week }^{2}}$ & 2 & 44 & $<0.001$ & $<0.001$ & $<0.001$ \\
\hline Cultivary & 2 & & 0.219 & 0.006 & $<0.001$ \\
\hline FLU rate ${ }^{y}$ & 4 & & 0.009 & 0.083 & 0.980 \\
\hline Lineary & 1 & & 0.001 & 0.496 & 0.910 \\
\hline Cultivar $\times$ rate $^{y}$ & 8 & & 0.046 & 0.365 & 0.351 \\
\hline $\mathrm{RC}$ vs. $\mathrm{AE}^{\mathrm{y}}$ & 1 & & 0.084 & 0.012 & 0.004 \\
\hline $\mathrm{RC}$ vs. $\mathrm{BS}^{\mathrm{y}}$ & 1 & & 0.438 & 0.144 & 0.002 \\
\hline AE vs. $\mathrm{BS}^{y}$ & 1 & & 0.331 & 0.001 & $<0.001$ \\
\hline Week $\times$ cultivar $^{2}$ & 4 & 88 & 0.576 & 0.052 & $<0.001$ \\
\hline Week $\times$ FLU rate ${ }^{2}$ & 8 & 88 & 0.041 & 0.001 & 0.722 \\
\hline Week $\times$ rate linear ${ }^{2}$ & 2 & 44 & 0.001 & 0.001 & 0.406 \\
\hline Week $\times \mathrm{RC}$ vs. $\mathrm{AE}^{\mathrm{z}}$ & 2 & 44 & 0.994 & 0.038 & 0.001 \\
\hline Week $\times$ RC vs. $\mathrm{BS}^{\mathrm{z}}$ & 2 & 44 & 0.316 & 0.707 & $<0.001$ \\
\hline Week $\times$ AE vs. $\mathrm{BS}^{\mathrm{z}}$ & 2 & 44 & 0.367 & 0.031 & $<0.001$ \\
\hline
\end{tabular}

${ }^{2}$ Results from MANOVA tests of hypothesis for within-subject (measurement taken repeatedly on each plant) effects.

${ }^{y}$ Tests the hypothesis that treatments (between-subjects effects) have no effect on the response variables, ignoring within-subject effects. This is the treatment effect when averaged over all weeks.

TRANSFORMATION option in the REPEATED statement compares two adjacent levels of time and was useful in determining when plant growth changed. This would not have been apparent with a univariate analysis for each observation point. A multivariate approach is well suited for studies involving plant growth regulators as the inhibition of gibberellin synthesis and the concomitant suppression of plant growth is not instantaneous but occurs over time. Flurprimidol provided the greatest height control for all cultivars tested during our experiment. Other findings conclude that 'Angel Eyes' is the cultivar least likely to respond to PGR application; it also had the lowest percentage of plants flowering when compared with other cultivars. 'Blue Stone' was the tallest cultivar in height and also appeared to respond to lower PGR rates. 'Blue Stone' also had the greatest percentage of flowering plants. 'Red Cloud' response in height and width usually ranged between the other two cultivars, and all three PGRs were able to effectively control height and width. Flowering percentages of 'Red Cloud' were similar to those of 'Blue Stone.'
Table 7. Effect of flurprimidol (FLU) rate on height of three cultivars of Tradescantia virginiana cultivars. Lower table represents $P$ values from profile analysis of plant height. These analyses of variance are for the transformed variables representing the differences between adjacent weeks. $\mathrm{AE}=$ 'Angel Eyes'; $\mathrm{BS}=$ 'Blue Stone'.

\begin{tabular}{|c|c|c|c|c|}
\hline \multirow{2}{*}{$\begin{array}{l}\text { Rate } \\
\left(\mathrm{mgL}^{-1}\right)\end{array}$} & \multicolumn{4}{|c|}{$\mathrm{Ht}(\mathrm{cm})$} \\
\hline & Week 2 & \multicolumn{2}{|c|}{ Week 4} & Week 6 \\
\hline 0 & $16.0^{2}$ & \multicolumn{2}{|c|}{15.2} & 23.6 \\
\hline 15 & 15.5 & \multicolumn{2}{|c|}{15.3} & 23.0 \\
\hline 30 & 16.0 & \multicolumn{2}{|c|}{15.7} & 22.6 \\
\hline 45 & 14.8 & \multicolumn{2}{|c|}{12.6} & 19.0 \\
\hline \multirow[t]{2}{*}{60} & 15.7 & & & 19.8 \\
\hline & & \multicolumn{2}{|c|}{ Week } & \\
\hline Treatments & & $2-4$ & $4-6$ & \\
\hline Mean $^{y}$ & & 0.002 & $<0.00$ & \\
\hline FLU rate ${ }^{x}$ & & 0.257 & 0.14 & \\
\hline Linear $^{\mathrm{x}}$ & & 0.106 & 0.01 & \\
\hline Cultivar $\times 1$ & $\operatorname{ate}^{x}$ & 0.384 & 0.11 & \\
\hline AE vs. BS & J rate $x$ & 0.050 & 0.74 & \\
\hline
\end{tabular}

${ }^{2}$ Average of all cultivars and replications for each treatment level and week.

${ }^{y} P$ values for change in plant height for adjacent weeks pooled over all treatments.

${ }^{x} P$ values for the main effects and interactions on the change in plant height between adjacent weeks.

\section{Literature Cited}

Bruner, L., G.J. Keever, C.H. Gilliam, and J.R. Kessler, Jr. 2000. Growth regulation of Canna $\times$ generalis 'Florence Vaughan.' J. Environ. Hort. 18:171-174.

Clough, E.A., A.C. Cameron, R.D. Heins, and W.H. Carlson. 2001. Growth and development of Oenothera fruticosa is influenced by vernalization duration, photoperiod, forcing temperature, 
Table 8. Effect of flurprimidol (FLU) rate on response variable of Tradescantia virginiana. Lower table presents $P$ values from profile analysis of $T$. virginiana response variable after treatment with FLU at ascending rates. These analyses of variance are for the transformed variables representing the differences in width between adjacent weeks.

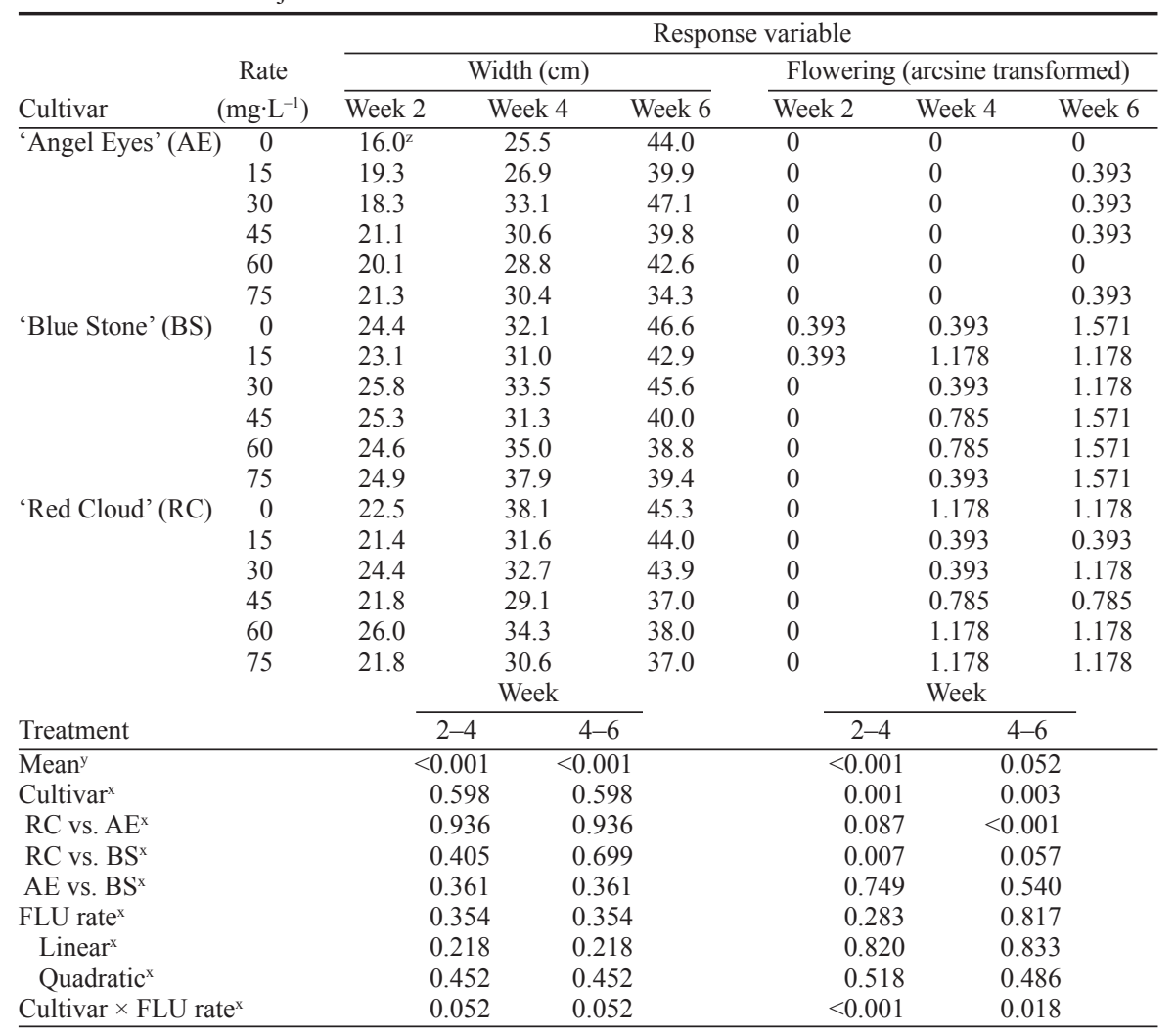

${ }^{2}$ Values are means of four replications for each treatments.

${ }^{y} P$ value for change in plant width for adjacent weeks pooled over all treatments.

${ }^{x} P$ values for the main effects and interactions on the change in width and arcsine transformed flowering of plants between adjacent weeks.

and plant growth regulators. J. Amer. Soc. Hort. Sci. 126:269-274.

Cox, D.A. and G.J. Keever. 1988. Paclobutrazol inhibits growth of zinnia and geranium. HortScience 23:1029-1030.

Davis, D. and A.S. Andersen. 1989. Post-production growth and flowering of triazole-treated Verbena rigida bedding plants. Gartenbauwissenschaft 54:109-112.

Fernandez, G.C.J. 1991. Repeated measures analysis of line-source sprinkler experiments. HortScience 26:339-342.

Gibson, J.L. and B.E. Whipker. 2001. Ornamental cabbage and kale growth responses to daminozide, paclobutrazol, and uniconazole. HortTechnology 11:226-230.

Huynh, H. and L.S. Feldt. 1970. Conditions under which mean square ratios in repeated measurements design have exact F-distributions. J.Amer. Stat. Assn. 65:1582-1589.

Keever, G.J. and C.H. Gilliam. 1994. Growth and flowering response of Butterfly-Bush to Cutless. J. Environ. Hort. 12:16-18.

Kim, S., A.A. De Hertogh, and P.V. Nelson. 1999. Effects of plant growth regulators applied as sprays or media drenches on forcing of Dutch- grown bleeding heart as a flowering potted plant. HortTechnology 9:629-633.

Littell, R.C. 1989. Statistical analysis of experiments with repeated measurements. HortScience 24:37-41.

Littell, R.C., P.R. Henry, and C.B. Ammerman. 1998. Statistical analysis of repeated measures data using SAS procedures. J. Animal Sci. 76:1216-1231.

Marini, R.P., D.S. Sowers, and M.C. Marini. 1995. Tree form and heading height at planting affect peach tree yield and crop value. HortScience 30:1196-1201.

Pobudkiewicz, A.K. and J. Nowak. 1994. The influence of flurprimidol and uniconazole on growth of the CMM dwarf Dianthus caryophyllus L. cv. Snowmass. J. Fruit Ornament Plant Res. 2:135-142.

Whipker, B.E., R.T. Eddy, and P.A. Hammer. 1995. Chemical growth retardant application to tuberous-rooted dahlias. HortScience 30:1007-1008.

Wulster, G.J. and T.M. Ombrello. 2000. Control of height and flowering of ixia hybrids as container plants. HortScience 35:1087-1088. 